\title{
The Mechanism of Char Ignition in Fluidized Bed Combustors
}

\author{
ROLAND V. SIEMONS
}

\author{
Department of Chemical Technology, University of Twente, Enschede, The Netherlands*
}

\begin{abstract}
Knowledge about ignition processes of coal in fluidized beds is of importance for the start-up and dynamic control of these combustors. Initial experiments in a transparent fluidized bed scale model showed the existence of a considerable induction period for the ignition of char, especially at low bed temperatures (e.g., 800-950K for bituminous coal). This paper focuses on char-ignition delay at these low temperatures. It is shown that temperature rise during ignition is not caused by coal particle diameter shrinkage but rather by an increase in reactivity. Analysis of the thermal ignition process leads to the conclusion that the process is noncritical, causing a gradual temperature rise without Semenov Jump. Consequences of this result for future research are expounded. Calculated values of the maximum inclination of the heat generation curve (heat release versus coal particle temperature) may be of use to the development of an adequate experimental device.
\end{abstract}

\section{INTRODUCTION}

After a coal particle is introduced in a fluidized bed combustor it needs some time to reach a stable temperature which is high enough above the bed temperature for maintaining a steady operation mode of the combustor. We call this period "charignition delay." (The distinction between ignition of char and of volatiles is briefly discussed below). Figure 1 shows the char-ignition delay as a function of bed temperature for cokes of a bituminous coal. (Data of this coal type are listed in Table 1.) This result is part of the research done by M. Radovanović et al. [1] at Twente University of Technology, which will be reported in due course [2]. Single coal particle ignition experiments were carried out in a two-dimensional transparent fluidized bed $\left(15 \times 200 \times 125 \mathrm{~mm}^{3}\right)$, constructed by W. Prins [2], which was electrically heated (Fig. 2). The fluidizing gas was a mixture of oxygen and nitrogen; the bed material consisted of $0.5 \mathrm{~mm}$ diam. alumina spheres. The construction made it

\footnotetext{
* The research reported upon in this paper was carried out at the Department of Mechanical Engineering, University of Twente.
}

possible to observe the coal particle visually, both directly and by TV-video. Slow-motion and freeze-frame analyses were carried out. In these experiments char-ignition delay was roughly approached by measuring the time lag from the introduction of the char particle until the moment at which the coal particle started to glow visibly. Also presented in Fig. 1 are estimations of heating times for nonreacting coal particles to reach the bed temperature (see Appendix). It is clear that at low bed temperatures the ignition takes more time than the heating does. Apart from bed temperature, char-ignition delay depends strongly on coal type and oxygen mol-fraction .

The phenomenon of char-ignition delay has important implications for the start-up and dynamic control of fluidized bed combustors. Central questions are

1. Does a minimum bed temperature above which coal feeding can be started exist, and if so, what are its physical determinants?

2. How can a simple experimental method by which the ignition behavior in fluidized beds can be tested for various coal types and circumstances be designed? 


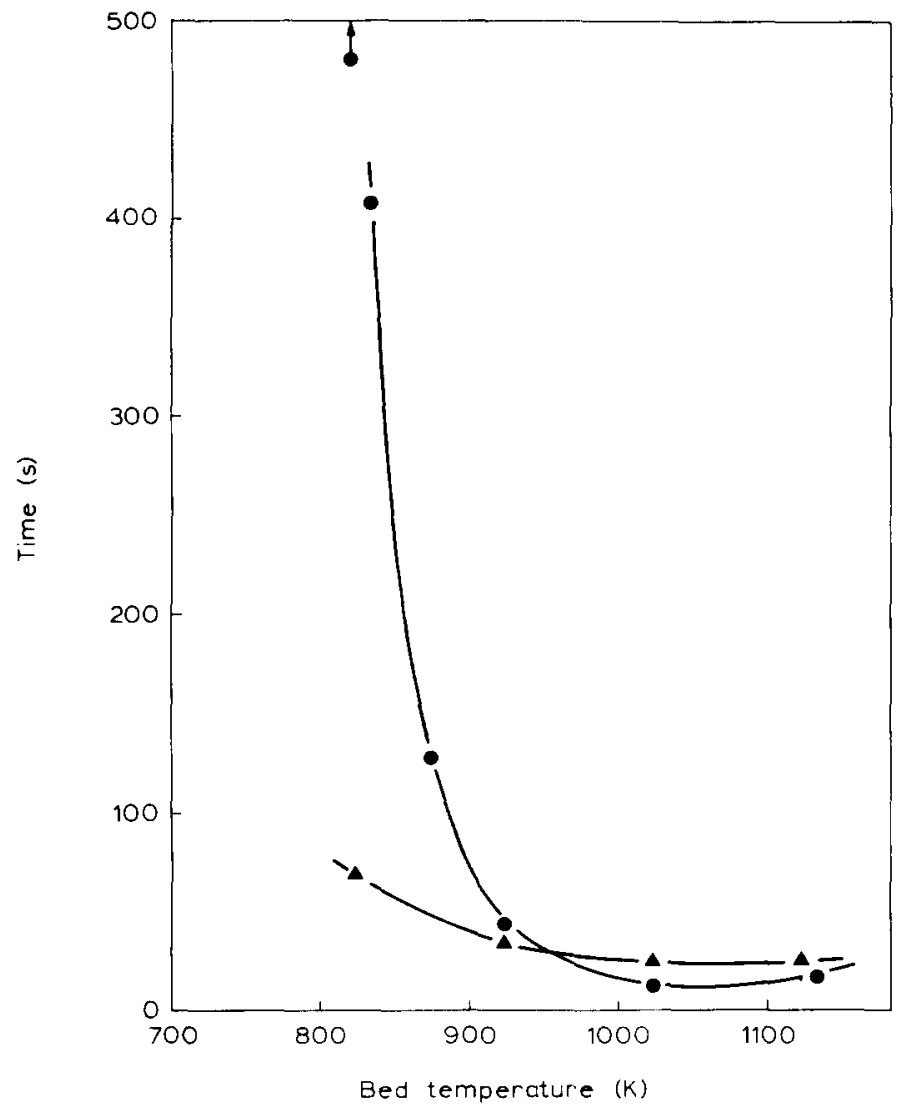

Fig. 1. Experimental data of char-ignition delay $(\boldsymbol{O})$ and estimated heating times $(\boldsymbol{\Delta})$ as a function of bed temperature ( $\uparrow$ : no ignition observed). $d=8.6 \mathrm{~mm}, U_{\mathrm{f}}=U_{\mathrm{mf}}+0.25 \mathrm{~m} / \mathrm{s}$, $X_{\mathrm{O}_{2}}=0.21$.

\section{TABLE 1}

Analysis of a Bituminous Coal

\begin{tabular}{cc}
\hline Proximate (\%) & 1.9 \\
Moisture & 35.3 \\
Volatile matter & 19.2 \\
Ash & 43.6 \\
Fixed carbon (by difference) & \\
\hline Ultimate (\%) & 64.9 \\
\hline Carbon & 3.4 \\
Hydrogen & 0.9 \\
Nitrogen & 0.8 \\
Sulfur & 9.0 \\
Oxygen & 0.1 \\
Chlorine & \\
\hline
\end{tabular}

These questions can only be answered if we have a physical understanding of the char-ignition delay.

When coal is introduced into a fluidized bed combustor devolatilization occurs and volatiles ignition as well as char ignition may take place in the same time interval and thus influence each other. Devolatilization might cause a pressure gradient preventing oxygen transport to and into the coal particle. To what extent this contributes to char-ignition delay is not part of this study. The consumption of oxygen by burning volatiles is another possible reason for char-ignition delay. However for a lignite it has been established by Prins et. al. [2] that volatile matter will only ignite at bed temperatures above $950 \mathrm{~K}$. It may be expected that volatile matter evolved from higher rank coals will ignite only at even higher bed temperatures. Therefore, since we are interested 


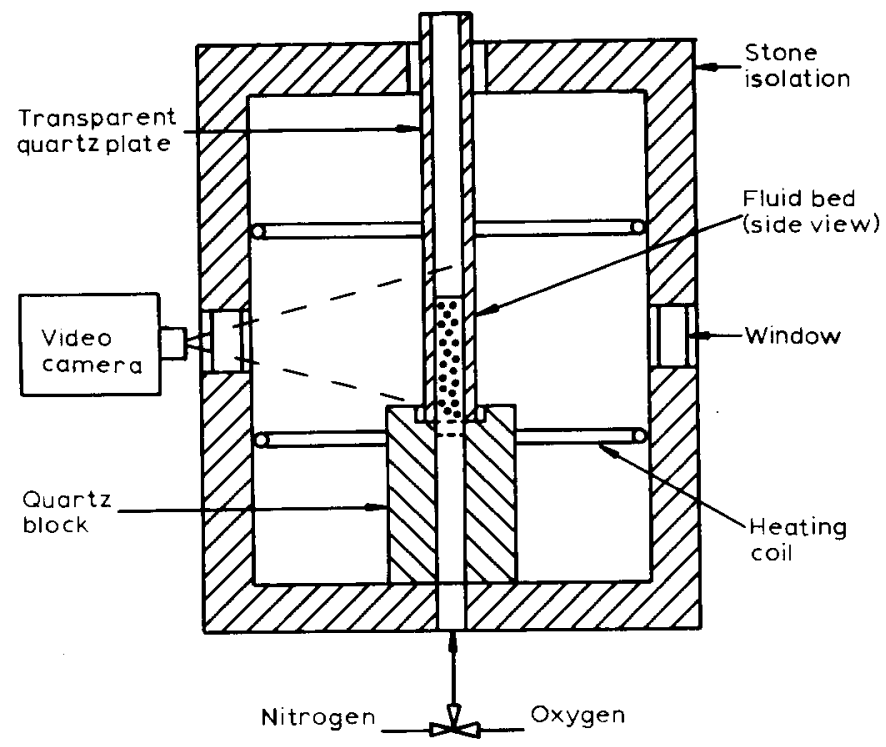

Fig. 2. Cross-sectional side view of the two-dimensional fluidized bed construction.

in the behavior at low bed temperatures, char ignition can be discussed independently of the ignition of volatile matter.

The study of ignition properties must be linked closely to the intended application of the fuel. Typical for fluidized bed combustion are uniform bed temperature and good heat transfer between the bed and inserted surfaces. Essenhigh [4] gives an extended review of the position of ignition research. But he does not mention any study concerning the mechanism of char ignition in fluidized beds.

\section{STATEMENT OF THE PROBLEM}

The char-ignition process is controlled by three almost independent characteristics: thermal inertia of the char particle, heat generation by combustion, and heat transfer between the char particle and the surrounding bed. They lead to the following equation (see list of symbols for meanings):

$m C_{\mathrm{p}} \partial T / \partial t=Q_{\mathrm{g}}-Q_{\mathrm{t}}$.

If carbon is converted partially to $\mathrm{CO}$ and partially to $\mathrm{CO}_{2}$ we may write for $Q_{\mathrm{g}}$,

$$
\begin{aligned}
Q_{\mathrm{g}}= & {\left[\mathrm{H}_{\mathrm{CO}_{2}} \Lambda_{\mathrm{CO}_{2}} / M_{\mathrm{CO}_{2}}\right)+\left(H_{\mathrm{CO}} \Lambda_{\mathrm{CO}} / M_{\mathrm{CO}}\right) } \\
& \left.-\left(h_{\text {char }}-h_{\text {graphite }}\right)\right] \dot{m}_{\mathrm{C}} \\
= & \left(H_{\mathrm{r}} / M_{\mathrm{C}}\right) \dot{m}_{\mathrm{C}},
\end{aligned}
$$

from the elements and $\Lambda_{j}$ is a gravimetric conversion coefficient, denoting the ratio of the mass flow of species $j$ and the total carbon mass flow $\dot{m}_{C} . H_{\mathrm{r}}$ is the enthalpy of the actual reaction per mole of carbon. The term ( $\left.h_{\text {char }}-h_{\text {graphite }}\right)$ is included since the enthalpy of formation of $\mathrm{CO}$ and $\mathrm{CO}_{2}$ is defined with reference to graphite instead of char. Its value can be measured by comparing the heat release of combusting graphite and char at a constant temperature. In this paper, however, it will be neglected.

If heat generation and transfer are plotted as a function of temperature the heat generation curve takes the shape of an S, owing to its dependence on both chemical kinetics and mass transfer, while the curve of heat transfer is almost a straight line. (Radiation plays only a minor role-see Section 3.) At their point of intersection, $\partial T / \partial t=0$. This point defines the overtemperature of the char particle (see Fig. 3). At the right-hand branch of the S-curve combustion is principally controlled by external oxygen transport, at the left-hand branch by chemical kinetics and intraparticle oxygen diffusion. Traditionally, only char particles that burn in the external oxygen transport regime are said to be ignited.

Most studies of the transition from the kinetic and pore diffusion controlled regime to the external transport regime, thus assessing ignition tem-

where $H_{j}$ is the enthalpy of formation of species $j$ 


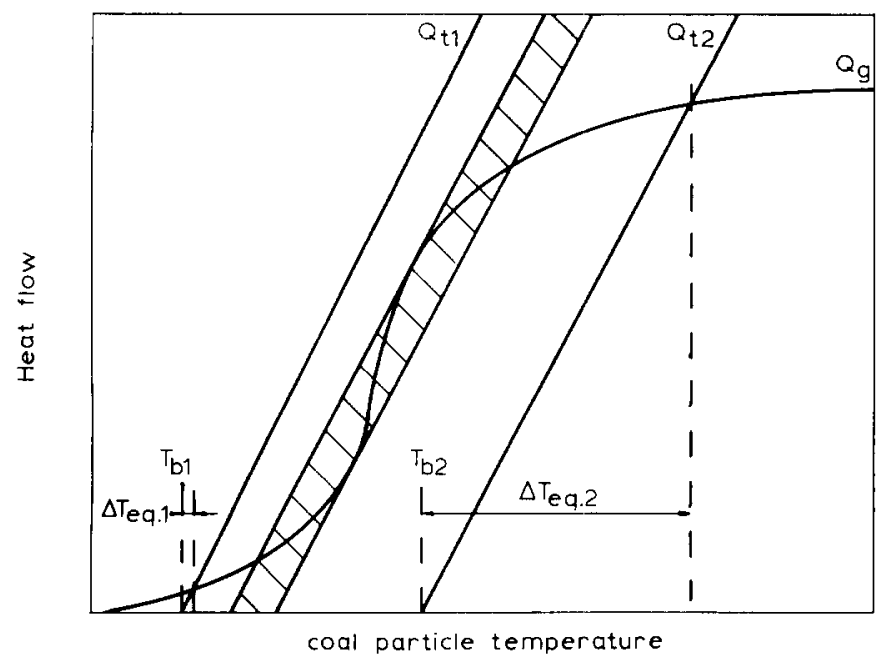

Fig. 3. Determination of the char particle overtemperature $\Delta T_{\text {eq }}$ by the char particle's heat generation and heat transfer from the char particle to the fluidized bed. Situations at low (1) and high (2) bed temperature, respectively. Shaded area: bistable region.

perature and delay, are limited to the evaluation of the "Tangency Criterion" which defines unstable points by $Q_{\mathrm{g}}=Q_{\mathrm{t}}$ and $\partial Q_{\mathrm{g}} / \partial T=\partial Q_{\mathrm{t}} / \partial T$. Naturally, such analysis is only possible for those devices where these points may exist, i.e., if the maximum inclination of the heat generation curve is steeper than the curve of heat transfer. After Vulis [5] we call this condition critical, whereas we call the other case, where unstable points do not exist, noncritical.
The difference between the two ignition modes has great consequences for the measurableness of ignition delay. Ignition delay, markedly exceeding the time required for the char particle to reach the bed temperature, must be due to relative changes between heat generation and transfer. The transformations conceivable with fluidized bed combustion are shown in Fig. 4. In case of critical conditions, while passing through an unstable point, the equilibrium char particle temperature

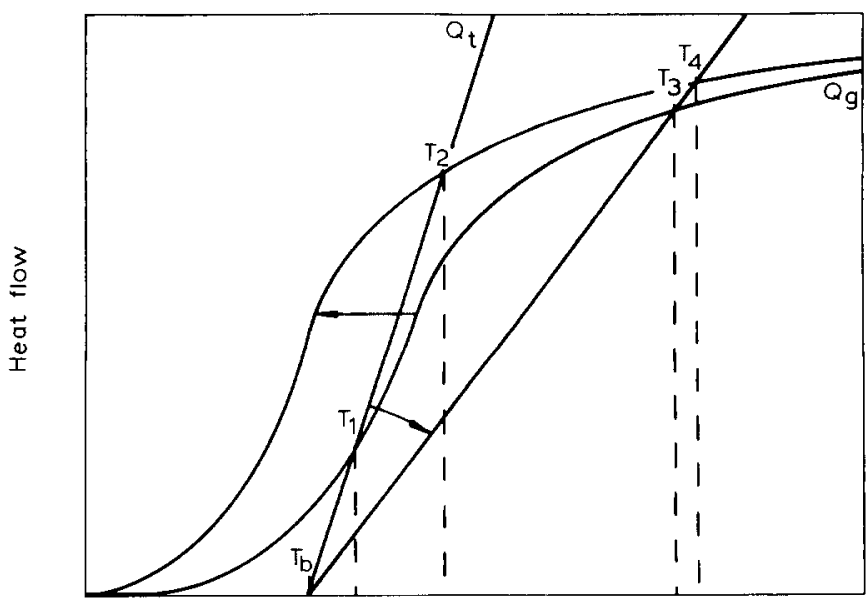

Coal particle temperature

Fig. 4. Possible changes of heat generation and heat transfer for an igniting char particle in a fluidized bed. $T_{1}$; char particle equilibrium temperature at $t=0 ; T_{2}$; same after change of heat generation rate; $T_{3}$; same after change of heat transfer rate; $T_{4}$; same after combined change of heat generation and transfer rate. 


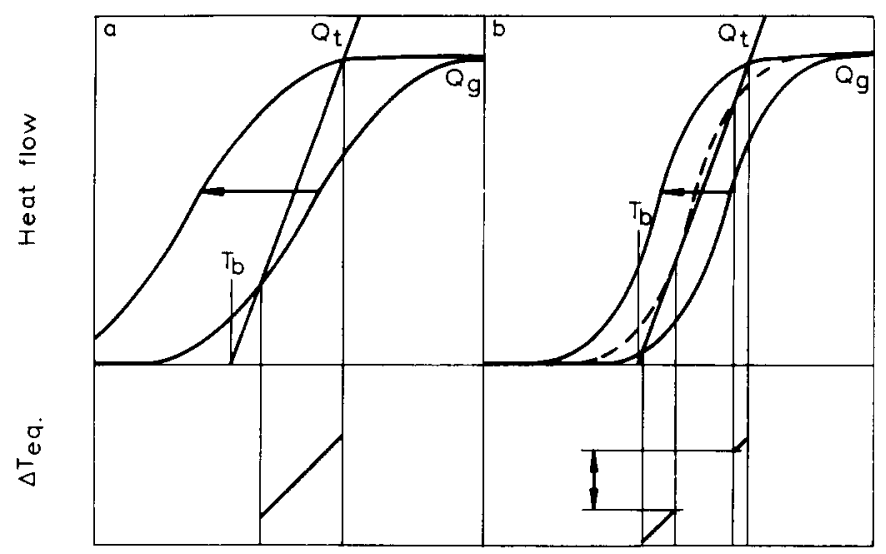

Coal particle temperature

Fig. 5. Two ignition modes. Noncritical (a) with continuous and critical (b) with discontinuous rising equilibrium char particle overtemperature, $\Delta T_{\mathrm{eq}}$.

changes discontinuously, thus causing a rapid temperature rise, the so-called Semenov Jump. Otherwise this jump will be absent with only a slow temperature change, (Fig. 5).

In this paper an attempt is made to answer two questions:

1. What are the physical properties that cause the changing relation between heat generation and heat transfer?

2. Are ignition conditions in fluidized bed combustors critical or noncritical?

We shall not immediately look for solutions to the unsteady-state equation [Eq. (1)], but rather investigate its quality.

\section{METHOD}

To evaluate these matters the inflection point of the heat generation curve, i.e., its temperature $T^{*}$ and inclination $\left(\partial Q_{\mathrm{g}} / \partial T\right)^{*}$, will be determined and compared to the position of the heat transfer curve. We shall look especially for the influence of char particle diameter, oxygen mol-fraction, and reactivity, the latter defined on actual mass base as

$$
R_{\mathrm{m}}=A \exp (-E / R T) C^{m} .
$$

The starting point of heat generation analysis is a conversion model for a spherical char particle, taking account of both external and internal oxygen transport as well as of the simultaneous conversion of oxygen within the particle. Thus, effects of pyrolysis and devolatilization are neglected. We shall assume that during ignition there is no ash layer and that the char particle is isothermal (see Appendix). Further, we assume that the char particle is homogeneous with respect to density, reactivity, and effective diffusivity at the moment it has attained the bed temperature. The equations derived in this section are meant for this point of time.

The mass balance for a spherical layer within the char particle reads

$$
\begin{aligned}
4 \pi r^{2} \partial r \rho \Lambda_{\mathrm{O}_{2}} A \exp (-E / R T) C^{m} \\
\quad=4 \pi \partial r \frac{\partial}{\partial r}\left(r^{2} D_{\mathrm{e}} \frac{\partial C}{\partial r}\right)-4 \pi r^{2} \partial r \frac{\partial C}{\partial t},
\end{aligned}
$$

with the boundary conditions

$r=0: \quad \partial C / \partial r=0, \quad C=C_{\mathrm{c}}$

and

$r=d / 2: \quad \partial C / \partial r=\left(k / D_{\mathrm{e}}\right)\left(C_{\mathrm{b}}-C_{\mathrm{s}}\right), \quad C=C_{\mathrm{s}}$.

In Eq. (3) the oxygen gravimetric conversion coefficient depends on the ratio of $\mathrm{CO}$ and $\mathrm{CO}_{2}$ production $z$,

$$
\Lambda_{\mathrm{O}_{2}}=\left(M_{\mathrm{O}_{2}} / M_{\mathrm{C}}\right)(z / 2+1) /(z+1) .
$$


Integration of Eq. (3) yields the carbon mass flux

$\dot{m}_{\mathrm{C}}=\left(4 \pi / \Lambda_{\mathrm{O}_{2}}\right) \int_{0}^{d / 2}\left[\frac{\partial}{\partial r}\left(r^{2} D_{\mathrm{e}} \frac{\partial C}{\partial r}\right)-r^{2} \frac{\partial C}{\partial t}\right] \partial r$

$\dot{m}_{\mathrm{C}}=4 \pi \rho A \exp (-E / R T) \int_{0}^{d / 2} r^{2} C^{m} \partial r$

If the regime is quasi-stationary,

$\frac{\partial C}{\partial t} \ll \frac{1}{r^{2}} \frac{\partial}{\partial r}\left(r^{2} D_{\mathrm{e}} \frac{\partial C}{\partial r}\right)$,

then, making use of the boundary conditions, we may write Eq. (5a) as

$\dot{m}_{\mathrm{C}}=\pi d^{2} k\left(C_{\mathrm{b}}-C_{\mathrm{s}}\right) / \Lambda_{\mathrm{O}_{2}}$.

The assumption is allowed in the stable combustion region, certainly if the ignition process turns out to be noncritical (see Appendix). Defining the effectiveness factor $\eta$ as $\eta=$ actual conversion velocity/conversion velocity if $C(r)=C_{\mathrm{s}}$, or, for homogeneous particles,

$\eta=\int_{0}^{d / 2} r^{2} C^{m} \partial r /\left(d^{3} C_{s}{ }^{m} / 24\right)$,

we find for Eq. (5b)

$\dot{m}_{\mathrm{C}}=\frac{1}{6} \pi d^{3} \rho A \exp (-E / R T) C_{s}{ }^{m} \eta$

The solution to $\eta$ as a function of the Thiele modulus $\phi$ is given by Aris [6,7] and Mehta [7]. We define the Thiele modulus as

$$
\begin{aligned}
\phi= & (d / 2)\left[(m+1) \rho \Lambda_{\mathrm{O}_{2}} \mathrm{~A}\right. \\
& \times \exp (-E / R T) C_{s}^{\left.m-1 /\left(2 D_{\mathrm{e}}\right)\right]^{1 / 2}} .
\end{aligned}
$$

Refashioned for this definition the solution to the effectiveness factor reads [8]

$\eta=(3 / \phi)[(\phi-\tanh \phi) / \phi \tanh \phi]$.

From Eqs. (6) the surface oxygen concentration $C$ s can be eliminated, and the carbon mass flux and subsequently the heat generation [Eq. (2)] can be determined as a function of temperature.
Besides the independent parameters to be varied freely, values of mass transfer and the $\mathrm{CO} / \mathrm{CO}_{2}$ ratio must be estimated. An empirical correlation given by Prins et al. [9] is used to calculate values of external mass transfer. Independent parameters are bed particle and char particle diameters, minimum fluidization velocity, and bed porosity.

The effective internal diffusivity depends on both particle porosity and temperature. Empirically Bliek [10] has established that

$D_{e} \sim \psi^{3} / 2.5$.

Taking account of both Knudsen and binary diffusion the temperature dependence is given by Leaurendeau [8]:

$D_{e} \sim\left[\left(1 / D_{\mathrm{k}}\right)+\left(1 / D_{\mathrm{b}}\right)\right]^{-1}$,

and

$D_{\mathrm{k}}=(\delta / 3)(8 \mathrm{RT} / \pi M)^{1 / 2}, \quad D_{b} \sim T^{1.75}$.

Since data for intraparticle diffusion at high temperatures are not at our disposal, we use these relations to extrapolate data obtained at room temperature.

The ratio of $\mathrm{CO}$ and $\mathrm{CO}_{2}$ production is calculated from a correlation given by Arthur [11]. Other correlations are available, e.g., Rossber [12], but the influence of this parameter will turn out to be rather small.

In contrast with our discussion of the heat generation curve and of the data necessary for its determination, a less extended reflection suffices for the curve of heat transfer from the char particle to the surrounding bed. A review concerning this problem is given by Prins et al. [13]. An important implication of their experimental work is that radiation plays only a minor role up to temperatures of $1200 \mathrm{~K}$. They present a relation for the maximum Nusselt number, which allows evaluation of the diameter and temperature dependence. (Heat transfer depends on the fluidization velocity. Fluidized bed combustors are expected to operate in the regime where heat transfer between fuel and bed material is maximum-Prins et al. [13].) Thus we find for heat transfer

$Q_{\mathrm{t}}=\left(\mathrm{Nu}_{\max } \lambda_{\mathrm{g}} / d_{\mathrm{b}}\right) \pi d^{2}\left(T-T_{\mathrm{b}}\right)$ 
In our laboratory the necessary data were measured for cokes of the bituminous coal and the small scale fluidized bed mentioned in Section 1 . All data are summarized in Table 2.

\section{AN ANALYTICAL SOLUTION}

The curve of heat transfer is a straight line through the bed temperature with an inclination of

$\partial Q_{\mathrm{l}} / \partial T=\pi d^{2} \mathrm{Nu} \lambda_{\mathrm{g}} / d_{\mathrm{b}}$.

Determination of the heat generation inflection point is more problematic. It is analytically determined by $\partial^{2} Q_{\mathrm{g}} / \partial T^{2}=0$. We shall shall assume that the reaction order $m=1$ since we prefer analytical to numerical solutions. Then Eq. (6) reduces to

$$
\begin{aligned}
\dot{m}_{\mathrm{C}}= & \pi d^{2}\left[\Lambda_{\mathrm{O}_{2}} / k+6 / \eta d \rho A\right. \\
& \times \exp (-E / R T)]^{-1} C_{\mathrm{b}}
\end{aligned}
$$

If the Thiele modulus $\phi>15$, Eq. (9) can be approximated by $\eta=3 / \phi$. Making use of this relation Eq. (12) is transformed to

$$
\begin{aligned}
\dot{m}_{\mathrm{C}}= & \pi d^{2}\left[\Lambda_{\mathrm{O}_{2}} / k+\left(\Lambda_{\mathrm{O}_{2}} / \rho D_{\mathrm{c}} A\right)^{1 / 2} /\right. \\
& \exp (-E / 2 R T)]^{-1} C_{\mathrm{b}} .
\end{aligned}
$$

\section{TABLE 2}

Data Used ${ }^{a}$

\begin{tabular}{lccc}
\hline Parameter & Value & Unit & Source \\
\hline$A$ & $48.7 \times 10^{3}(\mathrm{~K}) T_{\mathrm{b}}$ & $\mathrm{kg} / \mathrm{m}^{3}$ & \\
$D_{\mathrm{b}}\left(\mathrm{O}_{2}-\mathrm{N}_{2}\right)$ & $9.71 \times 10^{-10}$ & $\mathrm{~m}^{2} / \mathrm{s}$ & Refs. [8] and [19] \\
$d_{\mathrm{b}}$ & $0.5 \times 10^{-3}$ & $\mathrm{~m}$ & \\
$\delta$ & $350 \times 10^{-10}$ & $\mathrm{~m}$ & \\
$E$ & $141.5 \times 10^{6}$ & $\mathrm{~J} / \mathrm{kmol}$ & \\
$\epsilon$ & 0.4 & - & \\
$H_{\mathrm{Co}}$ & & & Ref. [18] \\
$H_{\mathrm{CO} 2}$ & & Ref. [18] \\
$\lambda_{\mathrm{g}}$ & 1 & Ref. [18] \\
$m($ reaction order $)$ & & - & Ref. [20] \\
$\nu_{\mathrm{g}}$ & 0.365 & - & \\
$\psi$ & 3800 & $\mathrm{~kg} / \mathrm{m}^{3}$ & \\
$\rho_{\mathrm{b}}$ & $1.1 \times 10^{3}$ & $\mathrm{~kg} / \mathrm{m}^{3}$ & \\
$\rho_{\mathrm{c}}$ & $17.01 T^{-0.646}$ & $\mathrm{~m} / \mathrm{s}$ & Ref. [11] \\
$U_{\mathrm{mr}}$ & $10^{3.4} \exp \left(-51.8 \times 10^{6}(\mathrm{~J} / \mathrm{kmol}) / R T\right)$ & - & \\
$z$ & & & \\
\hline
\end{tabular}

\footnotetext{
$a$ from

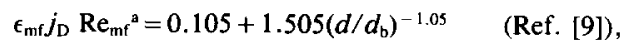

$a=0.35+0.29\left(d / d_{\mathrm{b}}\right)^{-0.50}$,

with

$j_{\mathrm{D}}=\left(k / U_{\mathrm{mf}}\right)\left(\nu_{\mathrm{g}} / D_{\mathrm{b}}\right)^{2 / 3}$,

$\operatorname{Re}_{\mathrm{mf}}=U_{\mathrm{mf}} d_{\mathrm{d}} /\left[\nu_{\mathrm{g}}\left(1-\epsilon_{\mathrm{mf}}\right)\right]$.

$\mathrm{Nu}_{\max }$ from

$\mathrm{Nu}_{\max }=c \mathrm{Ar}^{a} \quad$ (Ref. [13]),

$c=3.539\left(d / d_{\mathrm{b}}\right)^{-0.257}\left(0.844+0.0756 T_{\mathrm{b}} / 273(\mathrm{~K})\right)$,

$a=0.105\left(d / d_{\mathrm{b}}\right)^{0.082}$.
} 


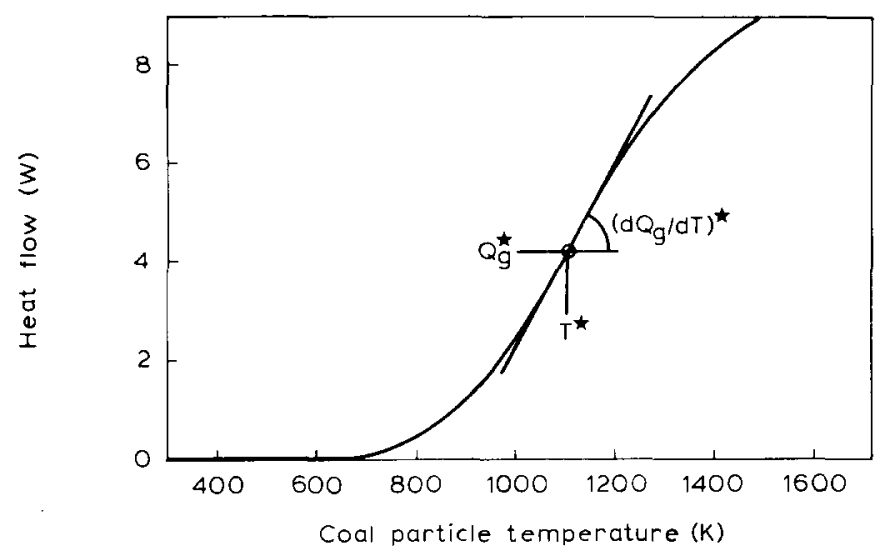

Fig. 6. Calculations of heat generation from the original equations [Eqs. (2), (9), (12)] and of the inflection point $(*)$ from Eqs. (14).

It turns out that the inflection point is indeed found at temperatures for which $\phi>15$, so that Eq. (13) proves to be a sound basis for the calculation of the heat generation [Eq. (2)]. Supposing that the logarithmic temperature dependence in Eq. (13) dominates the temperature dependence of the reaction enthalpy, the coefficient of mass transfer, and the oxygen gravimetric coefficient, the inflection point is found to be determined by the following implicit relations:

\section{$T^{*}$ by}

$$
\begin{aligned}
& {\left[\left(E / R+4 T^{*}\right) /\left(E / R-4 T^{*}\right)\right] \exp \left(-E / 2 R T^{*}\right)} \\
& \quad=\left(k^{2} / D_{\mathrm{e}} \rho A \Lambda_{\mathrm{O}_{2}}\right)^{1 / 2}
\end{aligned}
$$

$Q_{\mathrm{g}}^{*}$ by

$Q_{\mathrm{g}}^{*}=\pi d^{2}\left(k / \Lambda_{\mathrm{O}_{2}}\right)\left[\left(E / R-4 T^{*}\right) /(2 E / R)\right] C_{\mathrm{b}} H_{\mathrm{r}}$,

and the inclination by

$$
\begin{aligned}
\left(\partial Q_{\mathrm{g}} / \partial T\right)^{*}= & \pi d^{2}\left(k / \Lambda_{\mathrm{O}_{2}}\right)\left[\left(E^{2} / R^{2}-16 T^{* 2}\right) /\right. \\
& \left.\left(8 T^{* 2} E / R\right)\right] C_{\mathrm{b}} H_{\mathrm{r}} .
\end{aligned}
$$

The dominance of the exponential temperature dependence was verified by calculating the original heat-generation curve from Eqs. (2), (9), and (12) and comparing this with the inflection point calculated from Eq. (14). The supposition is allowed, as illustrated by Fig. 6 .

Explicit approximations for $T^{*}, Q_{\mathrm{g}}^{*}$, and $\left(\partial Q_{\mathrm{g}} /\right.$ $\partial T)^{*}$ clarify the importance of the various parameters. They read

$$
\begin{aligned}
& T^{*} \simeq(E / R) / \ln \left(\rho A \Lambda_{\mathrm{O}_{2}} D_{\mathrm{e}} / k^{2}\right), \\
& Q_{\mathrm{g}}^{*} \simeq \frac{1}{2} \pi d^{2}\left(k / \Lambda_{\mathrm{O}_{2}}\right) C_{\mathrm{b}} H_{\mathrm{r}}
\end{aligned}
$$

(which is half of the heat generated if the char particle burns while limited by external mass transfer), and

$$
\begin{aligned}
\left(\partial Q_{\mathrm{g}} / \partial T\right)^{*}= & \frac{1}{8} \pi d^{2}\left(k / \Lambda_{\mathrm{O}_{2}}\right)(\mathrm{R} / \mathrm{E}) \\
& \times\left[\ln \left(\rho A \Lambda_{\mathrm{O}_{2}} D_{\mathrm{e}} / k^{2}\right)\right]^{2} C_{\mathrm{b}} H_{\mathrm{r}} \\
\simeq & \frac{1}{8} \pi d^{2}\left(k / \Lambda_{\mathrm{O}_{2}}\right)\left(\mathrm{E} / \mathrm{RT}^{* 2}\right) C_{\mathrm{b}} H_{\mathrm{r}}
\end{aligned}
$$

We see that the activation energy is directly proportional to the inflection point temperature, while inversely proportional to the maximum inclination of the heat generation curve. The oxygen mol-fraction is proportional to the maximum inclination. The influence of particle dimensions is expressed in the coefficient of external mass transfer.

\section{RESULTS}

The questions raised in Section 2 will be discussed here successively. Figures 7-10 show the results of calculations concerning heat generation [Eqs. 


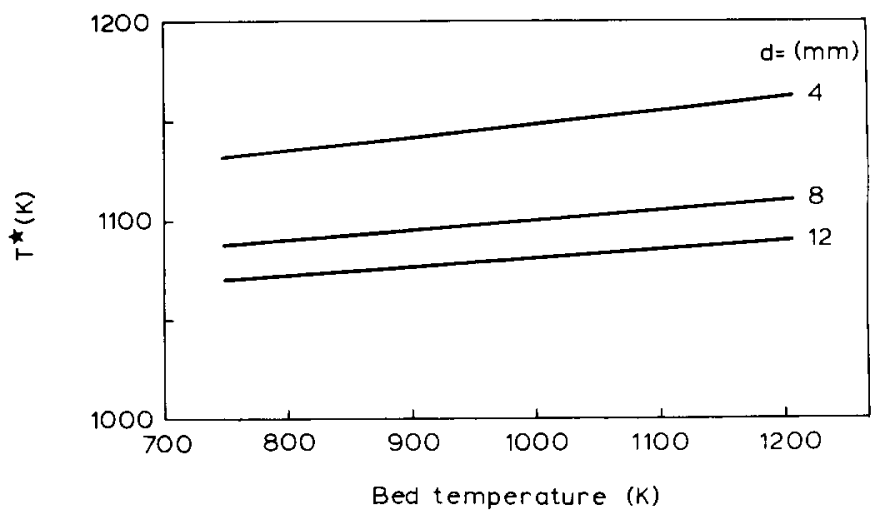

Fig. 7. Inflection point temperature as a function of bed temperature for 3 char particle diameters. $X_{\mathrm{O}_{2}}=0.21$.

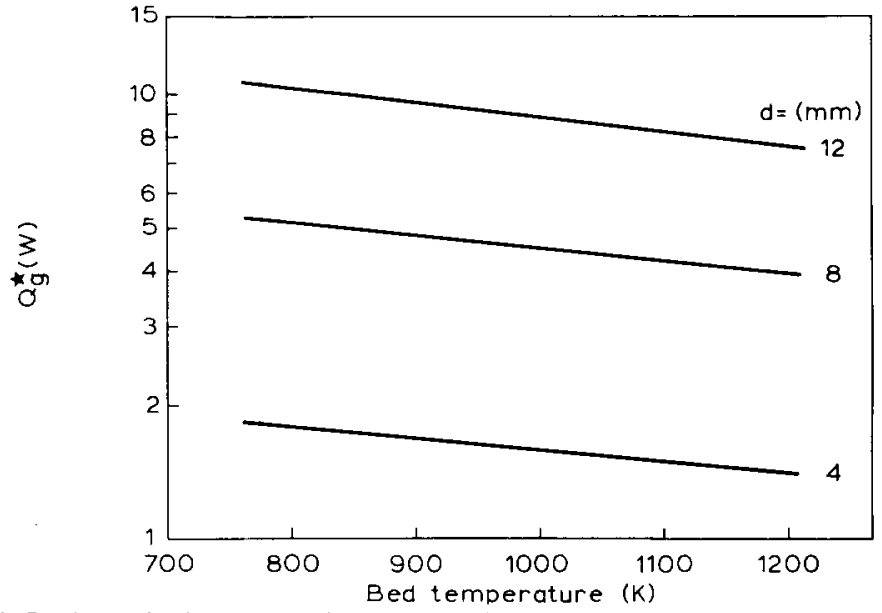

Fig. 8. Inflection point heat generation as a function of bed temperature for 3 char particle diameters. $X_{\mathrm{O}_{2}}=0.21$.

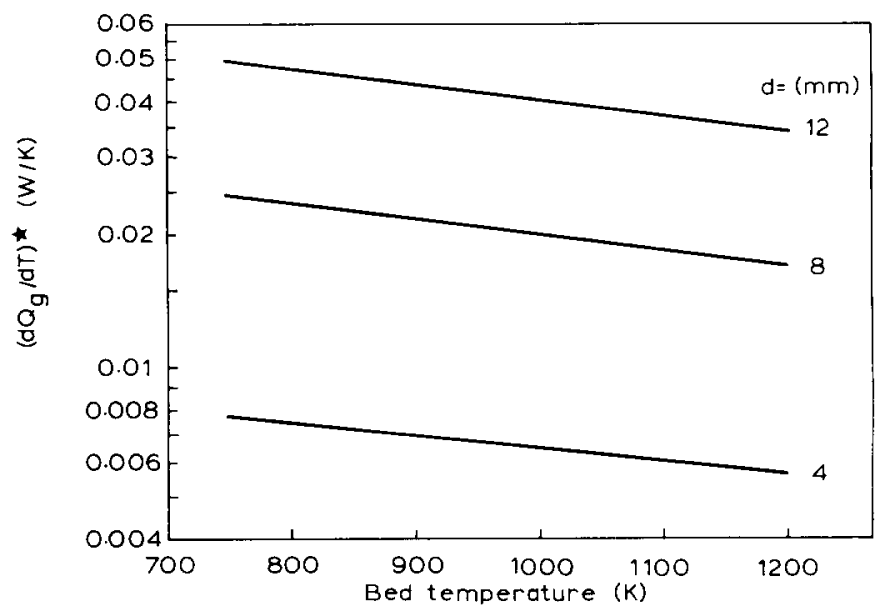

Fig. 9. Inflection point inclination as a function of bed temperature for 3 char particle diameters. $X_{\mathrm{O}_{2}}=0.21$. 


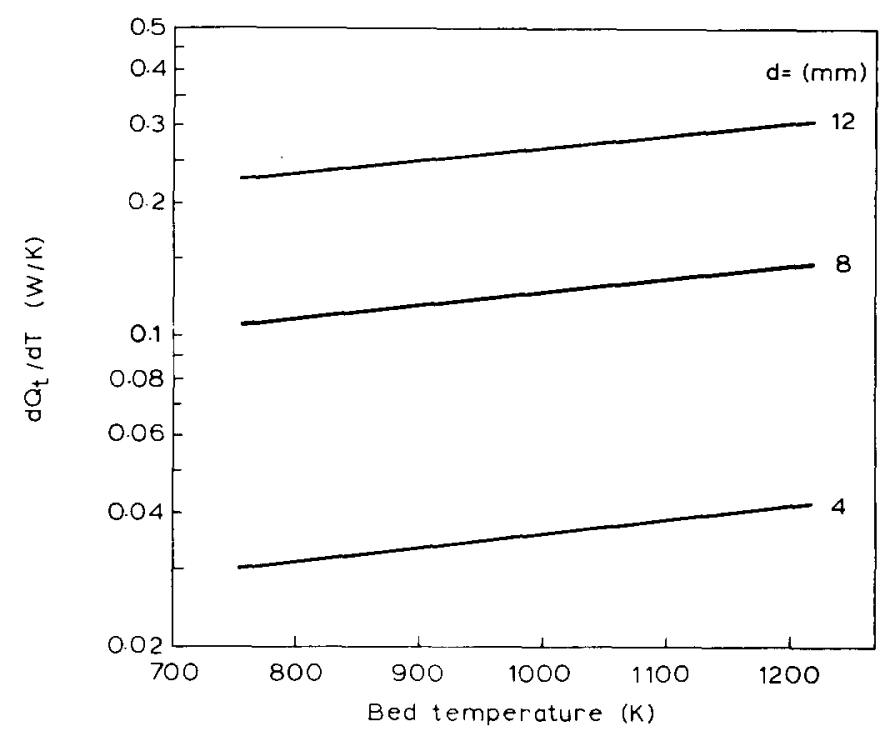

Fig. 10. Inclination of the heat transfer curve as a function of bed temperature for 3 char particle diameters. $X_{\mathrm{O}_{2}}=0.21$.

(14)] as well as heat transfer [Eq. (11)], as a function of bed temperature for 3 different char particle diameters. Assuming that the reaction order $m=1$ these calculations are valid in a first period after introduction of the char particle into the fluidized bed, as long as conversion has not caused serious inhomogeneities. The inflection point temperature lies between 1075 and $1160 \mathrm{~K}$. For bed temperatures below 1050-1110K, depending on char particle size, this means that in the first instance char particles will burn at relatively low temperatures in the kinetic and pore diffusion controlled regime. Nonetheless experiments at lower bed temperatures indicate a considerable char particle overtemperature after an induction period up to $400 \mathrm{~s}$ (see Fig. 1).

The reason for this remarkable fact might be decrease of heat transfer (see Fig. 4) caused by diameter shrinkage of the burning char particle. However, the heat generation inflection point of smaller char particles is situated at higher temperatures (see Fig. 7), so this cannot explain properly the phenomenon of ignition delay. Therefore, since the reason cannot be found in heat transfer, the heat generation inflection point must shift to lower temperatures as indicated in Fig. 11. We can imagine how this comes about. In a first period conversion leads to an increase of the char particle's internal surface area, and consequently to an increase of both the preexponential reactivity constant $A$ and the effective diffusivity $D_{\mathrm{c}}[8]$. For uniformly burning char particles, Eq. (15a) indicates how these parameters determine the decrease of the inflection point temperature.

Matters are more complicated, since in reality char particles do not burn uniformly, due to the oxygen concentration gradient within the char particle. Equation (3) is still valid, but for obtaining the carbon mass flux the integration of a radius dependent preexponential reactivity constant is required. Just as in the case of uniform combustion, the increase of this factor with radius and time leads to a growth of conversion in the kinetic and internal transport limited regime and, again, consequently to a decrease of the inflection point temperature. The initial conditions for an exact, numerical evaluation are still given by the equations derived in Sections 3 and 4.

From these considerations it is clear why the "Progressive Conversion Model' '[8], which starts from Eq. (3) but does not take time dependences into account, cannot be a proper model for fluidized bed combustion.

The remaining question is whether the ignition mode is critical or noncritical. By means of the model drawn up we are able to determine the 


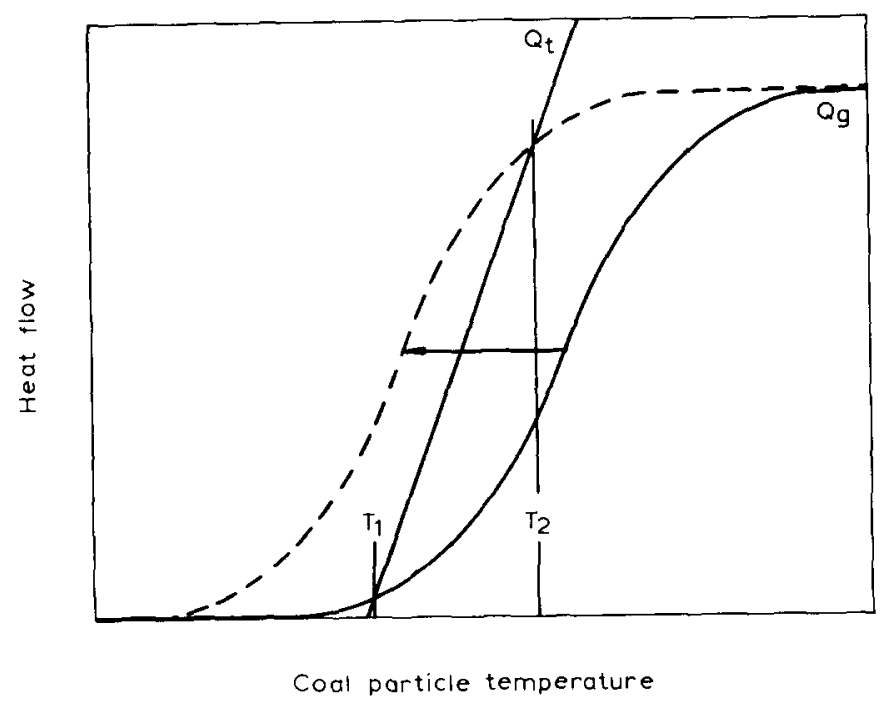

Fig. 11. Illustration of the mechanism causing char-ignition delay in fluidized bed combustors.

situation at the beginning of ignition and to formulate an expectation of the further development. For a certain char type and oxygen molfraction Figs. 9 and 10 show that the initial circumstances are noncritical, since for all bed temperatures the inclination of heat transfer is steeper than that of heat generation. The influence of the initial char particle size is made explicit in Fig. 12. In the diameter range from 3 to $15 \mathrm{~mm}$ the ratio of the inclinations of heat generation and transfer is unaffected by this diameter.

Since oxygen mol-fraction variations from 0.04 to 0.21 are demonstrated in fluidized bed combustors [14], ignition in oxygen lean zones is likely. The meaning of this mol fraction for the initial condition is shown in Fig. 13. It remains noncritical, while the ratio of the two inclinations may increase up to a factor of 25 .

An important reactivity parameter is the activation energy. For most char types its value lies between $50 \times 10^{6}$ and $320 \times 10^{6} \mathrm{~J} / \mathrm{kmol}$ [8]. So, since our calculations are based on an activation energy of $140 \times 10^{6} \mathrm{~J} / \mathrm{kmol}$, and the maximum inclination of the heat generation curve is inversely proportional to it, this inclination can be twice as steep as calculated. Still, initial conditions are noncritical. In our approach the type of char is not only defined by activation energy but also by specific mass, the preexponential reactivity con- stant, and internal diffusivity. The influence of the latter parameters, however, were not investigated in this study.

Equation (15d) shows that the decrease of the inflection point temperature causes an increase of the inflection point inclination. It seems possible that, though starting as a noncritical process, ignition becomes critical. We present arguments why during the whole ignition period, circumstances remain noncritical. The most unfavorable starting position for this thesis is at the lowest bed temperature at which ignition of the considered char type was observed, which is $825 \mathrm{~K}$. For uniform combustion the argument is easy. Let us assume that the inflection point temperature shifts to $825 \mathrm{~K}$. For an $8 \mathrm{~mm}$ char particle and $21 \%$ oxygen (the original inflection point temperature is 1090K-cf. Fig. 7), Eq. (15d) yields that the maximum inclination of heat generation increases by a factor

$$
\left(T_{\mathrm{o}}^{*} / T_{\mathrm{i}}^{*}\right)^{2}=(1090 / 825)^{2}=1.75,
$$

which is too small for the ignition process to become critical.

In the more realistic case of nonuniform combustion Eqs. (15) are not simply applicable, but must be adjusted. Instead of Eq. (9), we postulate a time dependent solution for the effectiveness 


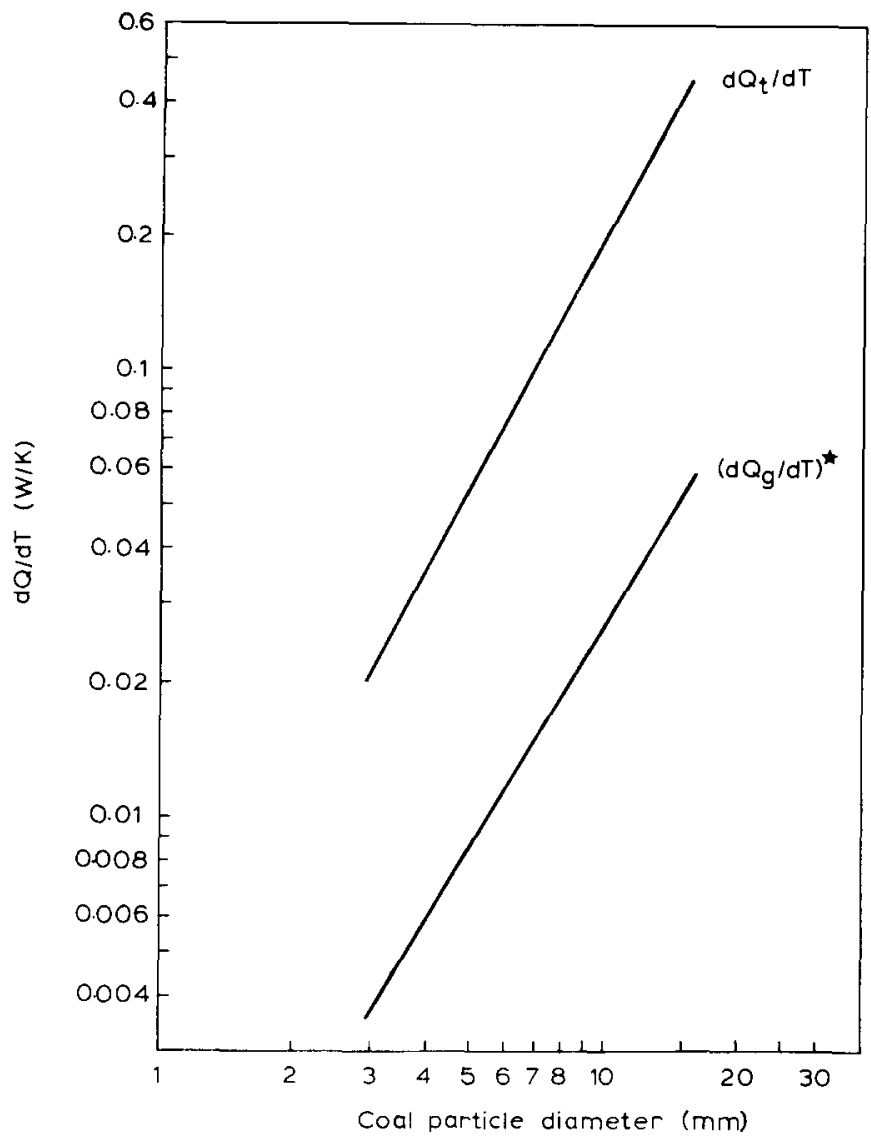

Fig. 12. Inclination of the heat transfer curve and heat generation curve at its inflection point as functions of char particle diameter. $X_{\mathrm{O}_{2}}=0.21, T_{\mathrm{b}}=1073 \mathrm{~K}$.

factor,

$\eta=C(t)(3 / \phi)[(\phi-\tanh \phi) / \tanh \phi]$,

on the understanding that the Thiele modulus is still defined by the initial values of the parameters in Eq. (8) and where $C(t)$ depends on the char burn-off history and therefore on time. The char burn-off history factor $C(t)$ may depend on bed temperature and initial char particle size. At $t=$ $0, C(t)=1$ to make this solution compatible with the solution given in Eq. (9). Thus it is assumed that the temperature dependence of the effectiveness factor remains the same during the ignition period. In a procedure analogous to the derivation of Eqs. (14) and (15) we now find

$T^{*} \simeq(E / R) / \ln \left[C(t)^{2} \rho D_{\mathrm{e}} A \Lambda_{\mathrm{O}_{2}} / k^{2}\right]$ and

$$
\begin{aligned}
\left(\partial Q_{\mathrm{g}} / \partial T\right)^{*}= & \frac{1}{8} \pi d^{2}\left(k / \Lambda_{\mathrm{O}_{2}}\right)(\mathrm{R} / \mathrm{E}) \\
& \times\left\{\ln \left[C(t)^{2} \rho A \Lambda_{\mathrm{O}_{2}} D_{\mathrm{e}} / \mathrm{k}^{2}\right]\right\}^{2} C_{\mathrm{b}} H_{\mathrm{r}} \\
\simeq & \frac{1}{8} \pi d^{2}\left(k / \Lambda_{\mathrm{O}_{2}}\right)\left(\mathrm{E} / \mathrm{RT}^{* 2}\right) C_{\mathrm{b}} H_{\mathrm{r}}
\end{aligned}
$$

where reactivity parameters are given by their initial values.

Equations (17c) and (15d) are identical, and therefore the same argument holds. The entire ignition process is noncritical. General validity of this thesis might be qualified by considering the influence of heat transfer by other bed materials. 


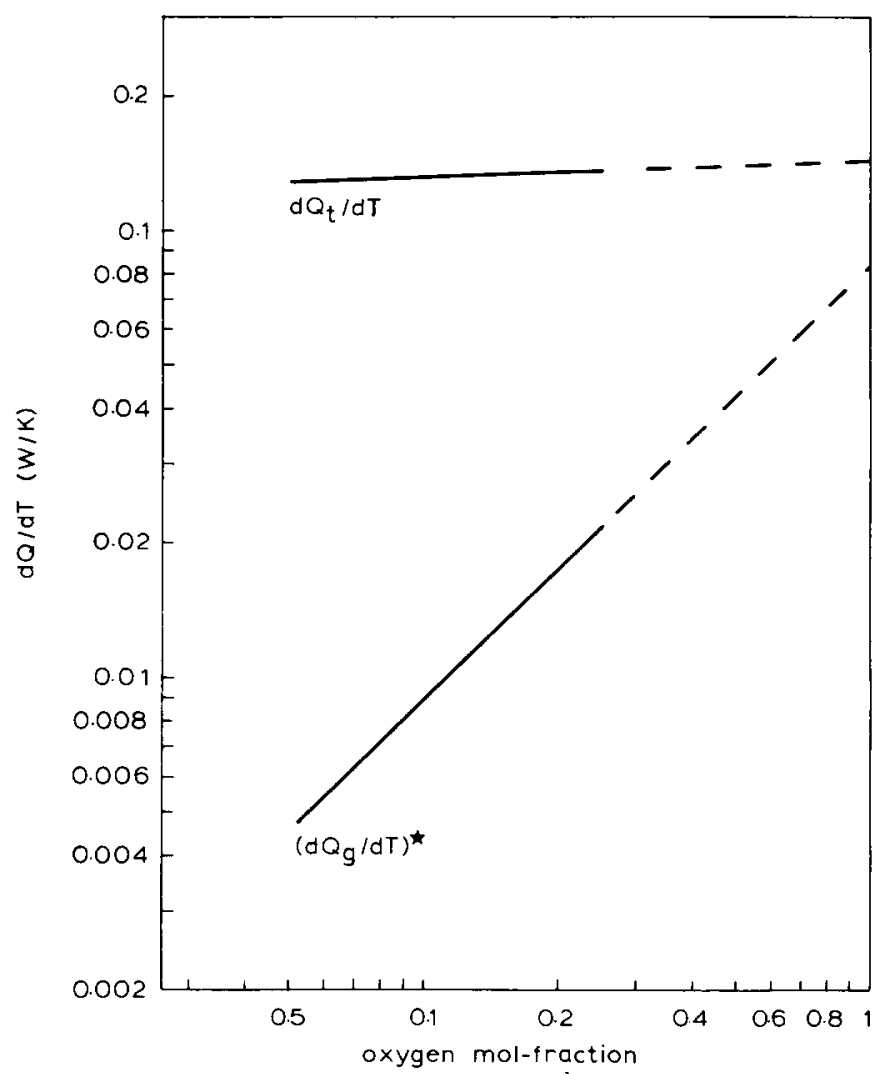

Fig. 13. Inclination of the heat transfer curve and heat generation curve at its inflection point as functions of the oxygen mol-fraction. - - calculated; - - , extrapolated. $d=8 \mathrm{~mm}, T_{\mathrm{b}}$ $=1073 \mathrm{~K}$.

\section{CONSEQUENCES AND POSSIBILITIES FOR FUTURE RESEARCH}

An important question for practical purposes is, How long does it take for newly introduced coal particles to attain an overtemperature which is sufficiently high to maintain or start up combustion? The temperature needed depends on the combustor's heat losses and will not be determined here. Theoretically, the question posed is, How fast and how far does the inflection point temperature of the heat generation curve decrease during ignition? We are unable to answer this question here, because the char burn-off history factor $C(t)$, introduced in Eqs. (16) and (17), is not yet known.

An attempt was made to measure the ignition delay by means of a transparent fluidized scale model and visual observation of the char particle [1-3]. But, since fluidized bed ignition appears to be a noncritical process without Semenov Jump, the moment of visible glowing cannot be an objective criterion. Still, this has drawn attention to the phenomenon of ignition delay and the importance of bed temperature.

Essentially there are two possibilities for future research. One is to make char particle temperatures measurable-for instance, by means of a freely moving thermocouple-and to record the temperature history. The other is to design a device with mass transfer similar to those in fluidized beds, but with poor heat transfer properties, in order to attain a critical ignition condition. Visual observation of the Semenov Jump will yield a good indication of the changes in heat generation. Values presented in Fig. 9 may serve as an 
indication of upper limits of heat transfer in such a device. The conical quartz tube, as used by Ragland et al. [21] may be developed further to fit these constraints.

\section{APPENDIX}

\section{Heating Times}

The energy balance for a spherical layer within the char particle reads

$$
\begin{gathered}
\left(H_{\mathrm{r}} / C_{\mathrm{p}} M_{\mathrm{C}}\right) A \exp (-E / R T) C^{m} \\
=\frac{\partial T}{\partial t}-\frac{1}{r^{2}} \frac{\partial}{\partial r}\left(r^{2} \frac{\lambda}{\rho C_{\mathrm{p}}} \frac{\partial T}{\partial r}\right)
\end{gathered}
$$

with the boundary conditions

$$
\begin{aligned}
& r=0: \quad \partial T / \partial r=0, \quad T=T_{\mathrm{c}} \\
& r=d / 2: \quad \partial T / \partial r=(\alpha / \lambda)\left(T_{\mathrm{b}}-T_{\mathrm{s}}\right), \quad T=T_{\mathrm{s}} .
\end{aligned}
$$

For nonreacting spheres heating up to the bed temperature Eq. (18) reduces to

$\partial T / \partial t=\frac{1}{r^{2}} \frac{\partial}{\partial r}\left(r^{2} \frac{\lambda}{\rho C_{\mathrm{p}}} \frac{\partial T}{\partial r}\right)$.

This equation is used to estimate the heating times of char particles to reach the bed temperature, shown in Fig. 3. It is clear that the temperature rise of reacting spheres is faster than that of nonreacting spheres. These estimations, therefore, provide upper values. For constant thermal diffusivity $\lambda / \rho C_{\mathrm{p}}$, Eq. (19) has been analytically solved and given as function of Biot and Fourier numbers [15]. Though the thermal diffusivity of char rises with increasing temperature, as may be inferred from Refs. [16] and [17], these solutions may still be of use to our purpose.

The calculated heating times are defined by the the time required for a $90 \%$ reduction of the original driving force: $\left(T_{\mathrm{b}}-T_{\mathrm{c}}\right) /\left(T_{\mathrm{b}}-T_{\mathrm{O}}\right)=$ 0.1 . Results as well as necessary data and their sources are listed in Table 3.

\section{Isothermal Ignition}

In this paper it is assumed that the char particle is isothermal. We shall show here why this is allowed.

From Eqs. (3) and (18) it follows that

$$
\begin{aligned}
- & \frac{1}{r^{2}} \frac{\partial}{\partial r}\left(r^{2} \frac{\lambda}{\rho C_{\mathrm{p}}} \frac{\partial T}{\partial r}\right)+\frac{\partial T}{\partial t} \\
= & \left(1 / M_{\mathrm{C}}\right)\left\{\frac{1}{r^{2}} \frac{\partial}{\partial r}\left[\left(r^{2} D_{\mathrm{e}} H_{\mathrm{r}} / \lambda C_{\mathrm{p}} \Lambda_{\mathrm{O}_{2}}\right) \frac{\partial C}{\partial r}\right]\right. \\
& \left.-\left(H_{\mathrm{r}} / \rho C_{\mathrm{p}} \Lambda_{\mathrm{O}_{2}}\right) \frac{\partial C}{\partial t}\right\} .
\end{aligned}
$$

Quasi-stationary integration yields

$$
\frac{\partial T}{\partial r}=\left(H_{\mathrm{r}} D_{\mathrm{e}} / \lambda \Lambda_{\mathrm{O}_{2}} M_{\mathrm{C}}\right) \frac{\partial C}{\partial r} \text {. }
$$

\begin{tabular}{|c|c|c|c|c|c|c|}
\hline$T_{\mathrm{b}}(\mathrm{K})$ & $C_{\mathrm{p}}(\mathrm{J} / \mathrm{kg} \mathrm{K})$ & $\lambda(\mathrm{W} / \mathrm{m} \mathrm{K})$ & $\alpha\left(\mathrm{W} / \mathrm{m}^{2} \mathrm{~K}\right)$ & $\mathrm{Bi}$ & Fo & $t(\mathrm{~s})$ \\
\hline 1100 & 2850 & 1.17 & 685 & 2.34 & 0.63 & 25 \\
\hline 1000 & 2600 & 0.83 & 645 & 3.11 & 0.56 & 28 \\
\hline 900 & 2350 & 0.49 & 600 & 4.90 & 0.46 & 35 \\
\hline 800 & 2100 & 0.19 & 550 & 1.83 & 0.38 & 69 \\
\hline
\end{tabular}

The integration constant is 0 , due to the boundary conditions at $r=0$. A second integration, making use of the boundary conditions, gives

$$
T_{\mathrm{s}}-T_{\mathrm{c}}=-\left(H_{\mathrm{r}} D_{\mathrm{e}} / \lambda \Lambda_{\mathrm{O}_{2}} M_{\mathrm{C}}\right)\left(\mathrm{C}_{\mathrm{s}}-C_{\mathrm{c}}\right),
$$

which is maximum for $C_{\mathrm{s}}=C_{\mathrm{b}}$ and $C_{\mathrm{c}}=0$.

TABLE 3

Heating times for $\left(T_{\mathrm{h}}-\mathrm{T}_{\mathrm{c}}\right) /\left(T_{\mathrm{b}}-T_{0}=0.1^{a}\right.$

${ }^{a} d=8 \mathrm{~mm} ; C_{\mathrm{p}}$ and $\lambda$ after Refs. [16] and [17] and evaluated at $T=\left(T_{\mathrm{c}}+T_{\mathrm{b}}\right) / 2$ 
Therefore,

$$
\begin{aligned}
\left(T_{\mathrm{c}}-T_{\mathrm{s}}\right)_{\max } & =\left(H_{\mathrm{r}} D_{\mathrm{e}} / \lambda \Lambda_{\mathrm{O}_{2}} M_{\mathrm{C}}\right) C_{\mathrm{b}} \\
& =\left(H_{\mathrm{r}} D_{\mathrm{e}} / \lambda \Lambda_{\mathrm{O}_{2}} M_{\mathrm{C}}\right)\left(X_{\mathrm{O}_{2}} P M_{\mathrm{O}_{2}} / R T_{\mathrm{b}}\right) .
\end{aligned}
$$

Again, maximum temperature differences exist for low bed temperatures, maximum oxygen molfraction, and conversion to $\mathrm{CO}_{2}$ rather than $\mathrm{CO}$. So we take $T_{\mathrm{b}}=825 \mathrm{~K}$ (the lowest bed temperature where char ignition was observed), $X_{\mathrm{O}_{2}}=$ 0.21 , and $z=0$. For atmospheric pressure we find $\left(T_{\mathrm{c}}-T_{\mathrm{s}}\right)_{\max }=0.7 \mathrm{~K}$, which has no influence on reactivity in the considered temperature range.

This result is obtained on the condition that the process is quasi-stationary, i.e., that

$$
\frac{1}{r^{2}} \frac{\partial}{\partial r}\left(r^{2} \lambda \frac{\partial T}{\partial r}\right) \gg \rho C_{\mathrm{p}} \frac{\partial T}{\partial t}
$$

and

$$
\frac{1}{r^{2}} \frac{\partial}{\partial r}\left(r^{2} D_{\mathrm{e}} \frac{\partial C}{\partial r}\right) \ll \frac{\partial C}{\partial t} .
$$

The moment at which these conditions are satisfied must be established experimentally. We expect that this moment will be attained after the period of rapid heating up to about the bed temperature.

\section{SYMBOLS}

$A$ preexponential reactivity constant, (kg/ $\left.\mathrm{m}^{3}\right)^{-m} / \mathrm{s}$

Ar $\quad g d_{\mathrm{b}}{ }^{3} \rho_{\mathrm{b}} / \rho_{\mathrm{g}} \nu_{\mathrm{g}}$, Archimedes number, dimensionless

$C$ oxygen concentration, $\mathrm{kg} / \mathrm{m}^{3}$

$C(t)$ char burn-off history factor, dimensionless

$C_{\mathrm{p}} \quad$ specific heat of char, $\mathrm{J} / \mathrm{kg} \mathrm{K}$

$D_{\mathrm{b}} \quad$ binary diffusivity, $\mathrm{m}^{2} / \mathrm{s}$

$D_{\mathrm{e}} \quad$ effective diffusivity, $\mathrm{m}^{2} / \mathrm{s}$

$D_{\mathrm{K}} \quad$ Knudsen diffusivity, $\mathrm{m}^{2} / \mathrm{s}$

$d$ char particle diameter, $\mathrm{m}$

$d_{\mathrm{b}} \quad$ bed particle diameter, $\mathrm{m}$

$E$ activation energy, $\mathrm{J} / \mathrm{kmol}$

$g$ gravity constant, $\mathrm{s} / \mathrm{m}^{2}$

$H_{j} \quad$ formation enthalpy of species $j$ from the elements, $\mathbf{J} / \mathrm{kmol}$
$H_{\mathrm{r}}$ reaction enthalpy per mole of carbon, $\mathrm{J} /$ kmol

$h_{j} \quad$ specific enthalpy of species $j, \mathrm{~J} / \mathrm{kg}$

$k$ external mass transfer coefficient, $\mathrm{m} / \mathrm{s}$

$M$ molecular mass, $\mathrm{kg} / \mathrm{kmol}$

$m \quad$ char particle mass, $\mathrm{kg}$ reaction order, dimensionless

$\dot{m}_{j} \quad$ mass flow of species $j, \mathrm{~kg} / \mathrm{s}$

$\mathrm{Nu}_{\max } \alpha_{\max } d_{\mathrm{b}} / \lambda_{\mathrm{g}}$, maximum Nusselt number, dimensionless

$Q_{\mathrm{g}} \quad$ heat flow generated by the char particle, $J /$ $s$

$P \quad$ pressure, $\mathrm{N} / \mathrm{m}^{2}$

$R \quad$ universal gas constant, $\mathrm{J} / \mathrm{kmol} \mathrm{K}$

$\operatorname{Re} \quad d U_{\mathrm{f}} / \nu_{\mathrm{g}}$, Reynolds number, dimensionless

$R_{\mathrm{m}} \quad$ reactivity on actual mass base (carbon mass flow/mass of actual present char), $\mathrm{s}^{-1}$

$r$ radius, $m$

$T$ char particle temperature, $\mathrm{K}$

$t$ time, s

$U \quad$ internal energy of the char particle, $\mathbf{J}$

$U_{\mathrm{f}} \quad$ fluidization velocity, $\mathrm{m} / \mathrm{s}$

$U_{\mathrm{mf}} \quad$ minimum fluidization velocity, $\mathrm{m} / \mathrm{s}$

$X$ mol-fraction, dimensionless

$z$ ratio of $\mathrm{CO}$ and $\mathrm{CO}_{2}$ production, $\mathrm{kmol} \mathrm{CO} /$ $\mathrm{kmol} \mathrm{CO}$

\section{Greek Symbols}

$\alpha \quad$ heat transfer coefficient, $\mathrm{J} / \mathrm{s} \mathrm{K} \mathrm{m}^{2}$

$\Lambda_{j} \quad$ gravimetric conversion coefficient for the formation of species $j$ (mass flow of species $j /$ total carbon mass flow), dimensionless

pore diameter, $\mathrm{m}$ bed porosity, dimensionless effectiveness factor, dimensionless Thiele modulus, dimensionless viscosity, $\mathrm{m}^{2} / \mathrm{s}$ thermal conductivity, $\mathrm{J} / \mathrm{s} \mathrm{K} \mathrm{m}$ char porosity, dimensionless specific mass, $\mathrm{kg} / \mathrm{m}^{3}$

\section{Indices}

b bed particle, bulk of the bed

C carbon

c char particle center 


$\begin{array}{ll}\text { e } & \text { effective } \\ \mathrm{f} & \text { fluidization } \\ \mathrm{g} & \text { generation, fluidizing gas } \\ \mathrm{i} & \text { ignition time } \\ j & \text { species } j \\ \mathrm{max} & \text { maximum } \\ \mathrm{mf} & \text { minimum fluidization } \\ \mathrm{O} & \text { oxygen } \\ \mathrm{p} & \text { char particle, constant pressure } \\ \mathrm{r} & \text { reaction } \\ \mathrm{s} & \text { char particle surface } \\ \mathrm{t} & \text { transfer } \\ * & \text { inflection point } \\ 0 & t=0\end{array}$

The author greatfully thanks Prof. $M . R a-$ dovanovic and Dr. W. Prins for their stimulating contribution to the research and discussion of the subject.

\section{REFERENCES}

1. Radovanović, M. Prins, W., and Siemons, R. V., Symposium on the Use of Lignites in Thermoenergetics (in Yugoslavian), Masinski Fakultet, Belgrade, 1983, pp. 93-102.

2. Prins, W., Fluidized Bed Combustion of a Single Carbon Particle, Ph.D. thesis, University of Twente, Enschede, 1987, Ch. 1.

3. Radovanović, M., in Advanced Course on Fluidized Bed Combustion, Dubrovnik 1984 (M. Radovanović, Ed.), Twente University of Technology (Dept. Mech. Eng), 1984, Ch. 5.

4. Essenhigh, R. H., in Chemistry of Coal Utilization (M. A. Elliot, Ed.), New York, 1981, 2nd Suppl. Vol., pp. 1285-1297.
5. Vulis, L. A., Thermal Regimes of Combustion, McGraw-Hill, New York, 1961.

6. Aris, R., Chem. Engng. Sci. 6:262-268 (1957).

7. Mehta, B. N. and Aris, R., Chem. Engng. Sci. 26:1699-1712 (1971).

8. Leaurendeau, N., Prog. Energy Combust. Sci. 4:211270 (1978).

9. Prins, W., Casteleyn, T. P., Draijer, W., and Van Swaaij, W. P. M., Chem. Engng. Sci. 40:481-497 (1985).

10. Bliek, A., Dissertation, Twente University of Technology, Enschede, 1984.

11. Arthur, J. R., Trans. Faraday Soc. 47:164-178 (1951).

12. Rossberg, M., and Wicke, E., Chemie-Ing.-Techn. 28:181-189 (1956).

13. Prins, W., Draijer, W., and Van Swaaij, W. P. M., 16th ICHMT Symposium (W. P. M. van Swaaij and N. H.Afgan, Eds.), Hemisphere, Washington, 1986, pp. 317-331.

14. Sinha, P. K., Datta, A. B., Nandi, S. S., and Bhaduri, D., Fuel 59:527-531 (1980).

15. Heisler, M. P., Trans. ASME 69:227-236 (1947).

16. Badzioch, S., Gregory, D. R., and Field, M. A., Fuel 43:267-280 (1964).

17. Melchior, E., and Luther, H., Erdöl Kohle Erdgas Petrochemie 28:379-385 (1975).

18. Landolt-Börnstein, Zahlenwerte und Funktionen aus Physik, Chemie, Astronomie, Geophysik und Technik, Springer Verlag, Berlin, 1955.

19. Weast, R. C. (Ed.), C.R.C. Handbook of Chemistry and Physics 63rd Ed., Boca Raton, 1982.

20. Dubbel's Taschenbuch für den Maschinenbau, Berlin, 1966.

21. Ragland, K. W., Jehn, T. C., and Yang, J. T., 18th Symposium (International) on Combustion, The Combustion Institute, 1981, pp. 1295-1303.

Received 23 September 1986; revised 6 May 1987 